\title{
CHEMICAL COMPOSITION AND ACARICIDAL ACTIVITIES OF Indigofera suffruticosa ESSENTIAL OIL AGAINST TWO-SPOTTED SPIDER MITE
}

Cleideana B. da Silva ${ }^{a}$, Marcilio M. de Moraes ${ }^{b}$, Claudio A. G. da Camarab ${ }^{b, c, * \odot, ~}$, Nicolle de C. Ribeiro ${ }^{c}$, João P. R. de Meloc, Vera L. M. de Lima ${ }^{a}$ and Daniela M. A. F. Navarro ${ }^{d}$

a'Departamento de Bioquímica, Universidade Federal de Pernambuco, 50670-420 Recife - PE, Brasil

'Departamento de Química, Universidade Federal Rural de Pernambuco, 52171-030 Recife - PE, Brasil

'Departamento de Agronomia, Universidade Federal Rural de Pernambuco, 52171-900 Recife - PE, Brasil

¿Departamento de Química Fundamental, Universidade Federal de Pernambuco, 50670-901 Recife - PE, Brasil

Recebido em 07/11/2018; aceito em 18/12/2018; publicado na web em 24/01/2019

\begin{abstract}
Laboratory bioassays on fumigation, ovicidal and oviposition deterrence activity of the essential oil from Indigofera suffruticosa and its constituents [eugenol, $(E)$-asarone, dill apiole, $(Z)$-asarone, thymol, (E)-nerolidol and safrole] against Tetranychus urticae were carried out. Components of Indigofera leaf oil were characterized by gas chromatography (GC) ad mass spectrometry (GCMS), which revealed the identification of 17 components, representing $97.7 \pm 0.6 \%$ of the total oil, with a high percentage of phenylpropanoids $(89.9 \pm 0.5 \%)$, among which eugenol $(45.6 \pm 0.4 \%)$ and $(E)$-asarone $(17.4 \pm 0.2 \%)$ were major constituents. The ovicidal activity and oviposition deterrence tests revealed that the essential oil as well as its main compounds affected the oviposition and hatchability of mite eggs. Eugenol and thymol were the most potent compounds and were approximately 225 -fold more potent than the oil. The acaricidal action exerted by sesquiterpenes and phenylpropanoids of the leaf oil is also discussed. The results suggest that the Indigofera oil and selected components associated with ovicidal activity and oviposition deterrence can serve as the basis for a promising agent that could be used in the formulation of a product for use against the T. urticae.
\end{abstract}

Keywords: essential oil; eugenol; (E)-asarone; Indigofera suffruticosa; Tetranychus urticae.

\section{INTRODUCTION}

Tetranychus urticae Koch (Acari: Prostigmata: Tetranychidae), commonly known as the two-spotted spider mite occurs both in the greenhouse and in the field and has a wide distribution in temperate and tropical regions. This mite is considered a major agricultural pest for attacking crops of worldwide economic importance, and become a critical problem in numerous agricultural production system, and yield losses can approach $15 \%$ for strawberries in the USA, $14 \%$ for corn in France, and $14-44 \%$ for cotton, ${ }^{1}$ also, in Brazil, particularly in Pernambuco in the municipality of Petrolina this pest has attacked various crops of ornamental and agricultural interest in the irrigated systems of culture of bean, raspberry, peach, tomato and cotton. ${ }^{2}$ The high reproductive potential, haplo-diploid sexual reproduction and short life cycle also facilitate the rapid development of resistance to many acaricides, ${ }^{3}$ thus the continuous use of synthetic acaricides fail to keep the mite population below economic threshold levels. The resistance of $T$. urticae to miticide abamectin and fenpyroximate in commercial fields of several crops was described. ${ }^{2}$

The use of conventional insecticides has grown dramatically and has caused great concern among various segments of society, which have demanded ecological alternatives, i.e. the use of natural products with low toxicity to mammals and low persistence in the soil, such as plant extracts, including essential oils. ${ }^{1}$ Natural products are a good alternative to control the dissemination of this mite pest. In recent years, essential oils and their constituents obtained from different parts of plants have been investigated for several biological activities against arthropods. ${ }^{4}$ Thus, the essential oils have been considered strong candidates in the search for a leading compounds for the formulation of botanical pesticides that could be used in pest control as an alternative to the synthetic pesticides due to its

*e-mail: claudio_agc@hotmail.com volatility, biodegradability and the low or no toxicity to mammals. In this context, a significant number of studies aimed at assessing the miticide potential of essential oils has been investigated by using fumigant toxicity assay, ${ }^{5,6}$ repellency and contact activity, ${ }^{7}$ reduction of egg oviposition and fecundity. ${ }^{8}$

Among the species with widespread on Mata Atlântica biome in Pernambuco, the members of the genus Indigofera (Fabaceae), stand out. This genus has approximately 700 species distributed in Africa, Asia, Australia and the Americas ${ }^{9}$ and I. suffruticosa Mill. is noted for its biological properties and use in folk medicine. Known as indigo, it is a plant native to the West Indies with a distribution in tropical and subtropical America. In Brazil, this plant is commonly found in the northeastern region, where infusions and decoctions of different parts of the plant are used in folk medicine as a febrifuge, purgative and sedative. ${ }^{10}$ Previous investigations of the biological potential of ethanol extract of the pods of this plant have revealed antioxidant activity ${ }^{11}$ and antimicrobial effects. ${ }^{12}$ However, no investigations of miticide potential have been reported with essential oil of indigo leaves from a fragment of Atlantic Forest in Pernambuco-Brazil.

This study aimed to evaluate the fumigant, ovicidal and oviposition deterrence of essential oils from the leaves of $I$. suffruticosa against $T$. urticae, assess the chemical composition of oil, as well as, investigate the relationship between toxicities of mains constituents and their blends.

\section{MATERIALS AND METHODS}

\section{Plant material}

Fresh leaves of I. suffruticosa were collected in the morning in the "Estiva" farm from the municipality of São Caetano (08¹9'33"S 3604'21'W), Pernambuco, Brazil. The plant was identified by Dr. Marlene Carvalho Alencar Barbosa from the Department of Botany, 
Federal University of Pernambuco (UFPE), Brazil. A voucher specimen was deposited with the identification number 45.217 at the UFP Geraldo Mariz Herbarium at UFPE.

\section{Essential oil extraction}

Fresh leaves $(100 \mathrm{~g})$ were submitted to hydrodistillation for $4 \mathrm{~h}$ in a Clevenger-type apparatus. The oil layers obtained were separated and dried over anhydrous sodium sulfate, weighed, stored in hermetically sealed glass containers and kept at $-5^{\circ} \mathrm{C}$ until further analysis. The oil yields $0.04 \pm 0.00 \%(\mathrm{w} / \mathrm{w})$ calculated from the weight of fresh material. All procedures were performed in triplicate.

\section{Chemicals}

Thymol, (E)-nerolidol, eugenol, safrole, dill apiole, $(E)$ and (Z)-asarone standard compounds used for the identifications of volatile components and in bioassays were purchased from Sigma-Aldrich.

\section{Instrumental analysis}

Quantitative GC and qualitative GC-MS analyses were carried out under the experimental conditions reported earlier. ${ }^{13}$ Quantitative GC analyses were carried out using a Hewlett-Packard 5890 Series II GC apparatus equipped with a flame ionization detector (FID) and a non-polar DB-5 fused silica capillary column (30 m x $0.25 \mathrm{~mm}$ x $0.25 \mu \mathrm{m}$ ). The oven temperature was programmed from 60 to $240{ }^{\circ} \mathrm{C}$ at a rate $3{ }^{\circ} \mathrm{C} \mathrm{min}^{-1}$. Injector and detector temperature was $260{ }^{\circ} \mathrm{C}$. Hydrogen was used as the carrier gas at a flow rate of $1 \mathrm{~mL} \mathrm{~min}{ }^{-1}$ in split mode $(1: 30)$. The injection volume was $0.5 \mu \mathrm{L}$ of diluted solution $(1 / 100)$ of oil in $n$-hexane. The amount of each compound was calculated from GC-FID peak areas in the order of DB-5 column elution and expressed as a relative percentage of the total area of the chromatograms. Analyses were carried out in triplicate.

The qualitative gas chromatography-mass spectrometry (GC-MS) (220-MS IT GC, Varian, Walnut Creek, CA, USA) analyses were carried out using a system with a mass selective detector, mass spectrometer in EI $70 \mathrm{eV}$ with a scan interval of $0.5 \mathrm{~s}$ and fragments from 40 to $550 \mathrm{Da}$ fitted with the same column and temperature program as that for the GC-FID analyses, with the following parameters: carrier gas $=$ helium; flow rate $=1 \mathrm{~mL} \mathrm{~min}^{-1}$; split mode (1:30); injected volume $=1 \mu \mathrm{L}$ of diluted solution $(1 / 100)$ of oil in $n$-hexane.

Identification of the components was based on $\mathrm{GC}$ retention indices with reference to a homologous series of $\mathrm{C}_{8}-\mathrm{C}_{40} n$-alkanes calculated using the van den Dool and $\mathrm{Kratz}^{14}$ equation and by computer matching against the mass spectral library of the GC-MS data system (NIST version 14 and WILEY version 11) and coinjection with authentic standards as well as other published mass spectra. ${ }^{15}$ Area percentages were obtained electronically from the GC-FID response without the use of an internal standard or correction factors.

\section{Biological material}

The mite T. urticae was identified by the acarologist Dr. Manoel Guedes C. Gondim-Júnior from Agronomy Department of Federal Rural University of Pernambuco. The mite T. urticae used for the bioassay were obtained from established laboratory colonies maintained for more than 10 years without any pesticide exposure, as describe in a previous work. ${ }^{5}$ The spider mites were reared on beans plants Canavalia ensiformes in the greenhouse, at temperature of $25 \pm 1{ }^{\circ} \mathrm{C}$, relative humidity of $65 \pm 5 \%$ and $12: 12 \mathrm{~h}$ photoregime.

\section{Fumigant assay}

The method to evaluate the fumigant activity of the oil was done as reported in previous work. ${ }^{6}$ Glass recipients with a capacity of $2.5 \mathrm{~L}$ were used as test arenas. Adult female spider mites placed on $C$. ensiformes leaf disks ( $2.5 \mathrm{~cm}$ in diameter) were exposed to I. suffruticosa volatile oils. A fine haired brush was used to transfer the mites onto the leaf disks. To maintain the turgor of the disks and avoid the escape of mites, the leaf disks were placed onto filter paper disks saturated with water in petri dishes $(9 \mathrm{~cm}$ in diameter). In the experiments all concentrations of essential oil or other products were tested in three replicates. Each replicate consisted of 30 specimens of T. urticae placed on 3 leaf disks ( 10 mites per disk) in a petri dish. The amounts of oil applied on a strip of filter paper $(5 \times 2 \mathrm{~cm})$ attached to the underside of the recipient lid by an automatic pipette, were of 0.02 to $12 \mu \mathrm{L}$, corresponding of 0.08 to $4.8 \mu \mathrm{L} \mathrm{L}^{-1}$ of air. Control glass recipients contained no essential oil or other products. Mortality was determined after $24 \mathrm{~h}$. Following exposure, the petri dishes with spider mites were then removed from the recipient arenas and the mites were touched slightly with a brush in order to determine mortality, and those with no sign of movement were considered as dead. The $\%$ mortality data for Indigofera oil was submitted to analysis of variance, with mean values compared by Tukey's test $[\mathrm{P} \leq 0.05]$. The same data were also analyzed with the Probit model using the POLO-PC program for the determination of $\mathrm{LC}_{50}$ values, with $95 \%$ confidence levels set for all experiments. ${ }^{13}$

\section{Effects of Indigofera suffruticosa oil on the fecundity of two- spotted spider mite}

The methodology used for the fecundity experiment was as reported by Pontes et al. ${ }^{16}$ with modifications. Glass containers with a capacity of $1.0 \mathrm{~L}$ were used as fumigation chambers. Five leaf disc from $C$. ensiformes $(1.5 \mathrm{~cm}$ in diameter) were placed equidistant in a petri dish (10 $\mathrm{cm}$ in diameter) which contained a disc of filter paper saturated with water in order to prevent the escape of mites and to maintain the turgor of the leaves. One adult female mite was placed on each leaf disc, then each petri dish was placed into the fumigation chamber. The essential oils or their major constituents were applied with the aid of automatic pipette into strips of filter paper $(5 \times 2 \mathrm{~cm})$ attached to the inner surface of the fumigation chamber lid. The concentration of the essential oil of I. suffruticosa $\left(0.08 \mu \mathrm{L} \mathrm{L}^{-1}\right.$ of air), and its major compounds, thymol (2.0 x 10 $0^{-4} \mu \mathrm{L} \mathrm{L}^{-1}$ of air), (E)-nerolidol $\left(0.1 \mu \mathrm{L} \mathrm{L}^{-1}\right.$ of air), safrole $\left(0.1 \mu \mathrm{LL}^{-1}\right.$ of air), dill apiole $\left(0.02 \mu \mathrm{LL}^{-1}\right.$ of air $),(Z)$-asarone (5.0 $\mu \mathrm{L} \mathrm{L}^{-1}$ of air), $(E)$-asarone $\left(8.0 \mu \mathrm{L} \mathrm{L}^{-1}\right.$ of air) and also of eugenol, which can be considered as the positive control $\left(6.4 \times 10^{-5} \mu \mathrm{L} \mathrm{L}^{-1}\right.$ of air) was the same that reduced the mite oviposition, but differ significantly from that of the control found in the bioassay that evaluated the toxicity by fumigation assay. For each tested treatment it was done a control group, because they were performed immediately after the fumigation bioassay. For each concentration were used 10 replicates. Fecundity was assessed after $24 \mathrm{~h}$ of exposure, by counting the number of eggs. The experimental design was randomized and the data obtained after meet the tests of normality and homogeneity of variance were analyzed by Tukey Test at $5 \%$ probability. ${ }^{17}$

\section{Ovicidal assay}

The methodology used for the ovicidal activity was that of Pontes et al. ${ }^{16}$ with modifications. Glass containers with a capacity of $1.0 \mathrm{~L}$ were used as fumigation chambers. Ten adult female spider mites were transferred to leaf discs from C. ensiformes $(2.5 \mathrm{~cm}$ in diameter) for obtaining the eggs. After a period of $12 \mathrm{~h}$, all females were removed 
from the leaves and their eggs counted, and only 30 eggs per leaf disc were left. The leaves were kept onto filter paper disc saturated with distilled water and placed in petri dishes $(8 \mathrm{~cm}$ in diameter and $1.5 \mathrm{~cm}$ height), as a manner to maintain the turgescence of the material. The experiments were performed in triplicate; a replicate consisted of 90 eggs of T. urticae placed on three leaf discs (30 eggs per disc) in a petri dish, thus a total of 270 eggs per treatment were used. The essential oils and their major constituents were applied with the aid of automatic pipette into strips of filter paper $(5 \times 2 \mathrm{~cm})$ attached to the inner surface of the fumigation chamber lid. The concentration of the essential oil of I. suffruticosa and its major compounds, as well as that of the positive control was $4.8 \mu \mathrm{L} \mathrm{L}^{-1}$ of air, in relation to the concentration of oil responsible for $95 \%$ mortality of the adults in the bioassay of toxicity. The petri dishes containing the eggs were exposed to vapors of oils, to the major constituents and to a positive control, for $24 \mathrm{~h}$; then, the petri dishes were removed from the fumigation chambers, and after $96 \mathrm{~h}$ the percentage of viable eggs and hatch were evaluated. Three repetitions were performed. Data of viability, after meet the tests of normality and homogeneity of variance, were subjected to analysis of variance and means were compared by Tukey test at $5 \%$ probability. ${ }^{17}$

\section{Comparative toxicity of compounds}

The methodology used to investigate the potential contribution of each constituent to the toxicity of the oil blend was as reported by Moraes et al. ${ }^{18}$ Seven compounds of the oil, included the principal constituents, were selected and their fumigant activities were evaluated individually and in the form of a complete blend. A blend was also prepared with all seven constituents as well as blends removing one constituent at a time, based on the natural composition of the oil indicated by GC-MS and tested at the concentration at which the pure oil caused $\geq 95 \%$ mortality. The toxicities of the complete and incomplete blends were statistically compared with that of I. suffruticosa oil.

\section{RESULTS AND DISCUSSION}

\section{Chemical composition of I. suffruticosa leaves}

Hydrodistillation of the leaves of I. suffruticosa provided a viscous, yellow oil with a strong odor and a yield of $0.04 \pm 0.00 \%$ $(\mathrm{w} / \mathrm{w})$. Table 1 lists the constituents identified and respective retention indices according to the order of elution in a DB-5 capillary column.

Seventeen compounds representing $97.7 \%$ of the total oil were identified by GC-MS. Phenylpropanoids $(89.9 \pm 0.5 \%)$ were the predominant chemical class in the oil, followed by sesquiterpenes $(6.4 \pm 0.1 \%)$ and monoterpenes $(1.4 \pm 0.1 \%)$. The principal component of the oil was eugenol $(45.6 \pm 0.4 \%)$, followed by $(E)$-asarone $(17.4 \pm 0.2 \%)$ and dill apiole $(10.6 \pm 0.2 \%)$. The phenylpropanoids and monoterpenes in the essential oil of another species of the genus Indigofera (I. microcarpa) were not detected. However, large amounts of sesquiterpenes (83.7\%) were found, among which $\beta$-caryophyllene (56.0\%) and $\alpha$-humulene $(25.1 \%)$ were the main constituents. ${ }^{19}$ Differences in the consituents of essential oils from species of the same genus (Indigofera) may be explained by genetic, physiological and environmental factors as well as geographical origin and geographical distances, which can play an important role in the assembly of molecules and the chemical composition of essential oils. ${ }^{20}$

Table 1. Percentage composition (\% $\pm \mathrm{SD}$ ) of essential oils from Indigofera suffruticosa leaves

\begin{tabular}{|c|c|c|c|c|c|}
\hline & Compound & $\mathrm{RI}^{\mathrm{a}}$ & $\mathrm{RI}^{\mathrm{b}}$ & Concentration $(\%)$ & Method of identification \\
\hline 1 & Methyl chavicol & 1194 & 1195 & $5.2 \pm 0.1$ & RI, MS \\
\hline 2 & Safrole & 1288 & 1285 & $0.1 \pm 0.0$ & RI, MS, CI \\
\hline 3 & Thymol & 1293 & 1289 & $1.4 \pm 0.1$ & RI, MS, CI \\
\hline 4 & Eugenol & 1352 & 1356 & $45.6 \pm 0.4$ & $\mathrm{RI}, \mathrm{MS}, \mathrm{CI}$ \\
\hline 5 & Croweacin & 1452 & 1457 & $5.4 \pm 0.3$ & RI, MS \\
\hline 6 & $\alpha$-Patchoulene & 1458 & 1454 & $0.8 \pm 0.0$ & RI, MS \\
\hline 7 & $(E)-\beta$-Ionone & 1483 & 1487 & $2.3 \pm 0.2$ & RI, MS \\
\hline 8 & cis-Eudesma- 6,11-dieno & 1494 & 1489 & $0.7 \pm 0.0$ & RI, MS \\
\hline 9 & Elemicin & 1552 & 1555 & $0.8 \pm 0.0$ & RI, MS \\
\hline 10 & (E)-Nerolidol & 1557 & 1561 & $0.4 \pm 0.0$ & RI, MS, CI \\
\hline 11 & (E)-Isoelemicin & 1568 & 1568 & $0.3 \pm 0.0$ & RI, MS \\
\hline 12 & (Z)-Asarone & 1620 & 1616 & $1.6 \pm 0.1$ & RI, MS, CI \\
\hline 13 & Dill apiole & 1625 & 1620 & $10.6 \pm 0.2$ & RI, MS, CI \\
\hline 14 & $\gamma$-Eudesmol & 1635 & 1630 & $1.0 \pm 0.0$ & RI, MS \\
\hline 15 & $\beta$-Eudesmol & 1645 & 1649 & $1.2 \pm 0.1$ & RI, MS \\
\hline 16 & 4,6-Dimetoxi-5-vinyl-1,2-benzoioxide & 1648 & 1653 & $2.9 \pm 0.1$ & RI, MS \\
\hline \multirow[t]{5}{*}{17} & (E)-Asarone & 1675 & 1675 & $17.4 \pm 0.2$ & RI, MS, CI \\
\hline & Monoterpenes & & & $1.4 \pm 0.1$ & \\
\hline & Sesquiterpenes & & & $6.4 \pm 0.1$ & \\
\hline & Phenylpropanoids & & & $89.9 \pm 0.5$ & \\
\hline & Total & & & $97.7 \pm 0.6$ & \\
\hline
\end{tabular}

$\mathrm{RI}^{\mathrm{a}}=$ Retention indices calculated from retention times in relation to those of a series of $n$-alkanes on a $30 \mathrm{~m}$ DB-5 capillary column. RI $=$ Linear retention indices from the literature. SD = Standard deviation, RI: retention index; MS: mass spectroscopy; CI: Co-injection with authentic compounds. 
A study by a research group in the state of Ceará (northeast Brazil) reports phytol (75.8\%) as the main constituent of essential oil from the leaves of $I$. suffruticosa, followed by fatty acid esters $(12.8 \%)$ and aliphatic compounds $(8.2 \%) .{ }^{11}$ No similarities are found between these data and those reported for the leaf oil of I. suffruticosa that occurs in the state of Pernambuco. The compounds identified in our analysis pertain to the monoterpene, sesquiterpene and phenylpropanoid chemical classes, whereas those identified in the I. suffruticosa oil from Ceará were basically linear hydrocarbons, fatty acids and diterpenes.

The major constituent in the oil reported by the group in the state of Ceará (phytol) is probably a product of the degradation of chlorophyll, the presence of which is explained by external factors, such as changes in temperature and excessive drying of the vegetal matrix, as well as endogenous factors, such as the action of the enzyme chlorophyllase. ${ }^{21}$

\section{Acaricidal activity of Indigofera suffruticosa essential oil}

Table 2 displays the toxicities of the I. suffruticosa oil, selected constituents and its full mixture (FM).

Vapours of the essential oil from the leaves of I. suffruticosa were toxic to adult $T$. urticae females, causing $96.6 \%$ mortality at a concentration of $4.8 \mu \mathrm{L} \mathrm{L}^{-1}$ of air. The linear regression analysis of the I. suffruticosa oil revealed that the mean lethal concentration $\left(\mathrm{LC}_{50}\right)$ of the leaf oil by fumigation was estimated at $0.90 \mu \mathrm{L}^{-1}$ of air. Due to the method used, the toxicity observed for the oil can be attributed to vapour penetration of the chemical constituents through the respiratory system of the mite.

Among the seven chemical constituents selected from I. suffruticosa oil, only $(E)$ - and $(Z)$-asarone demonstrated lower toxicity $\left(\mathrm{LC}_{50}=6.64 \mu \mathrm{L} \mathrm{L}-1\right.$ of air and $8.51 \mu \mathrm{L} \mathrm{L}-1$ of air, respectively) than that displayed by the essential oil. In contrast, eugenol $\left(\mathrm{LC}_{50}=0.004 \mu \mathrm{L} \mathrm{L}^{-1}\right.$ of air) and thymol $\left(\mathrm{LC}_{50}=0.002 \mu \mathrm{L}^{-1}\right.$ of air) exhibited the greatest fumigant action, greater even than that of the essential oil. Several studies have shown positive fumigation results for essential oils and their constituents against mites. ${ }^{1}$ The present preliminary data on the toxicity of thymol and eugenol are in agreement with findings described in the literature. Lippia sidoides and its component thymol ${ }^{22}$ exhibited potent acaricidal activity by fumigation against $T$. urticae. Moraes et al. ${ }^{18}$ found that T. urticae was more susceptible to eugenol by fumigation than the other constituents tested, indicating that the effect of this compound was largely due to the action of the volatile phase.

The toxicity of the full mixture (FM) prepared with select constituents in the relative proportion at which these compounds were identified in the essential oil through GC-MS was 1.7-fold greater than that of the Indigofera oil, but demonstrated the same level of toxicity found for the phenylpropanoids, eugenol and thymol. The smaller effect of the I. suffruticosa oil in comparison to the mixtures of select compounds may be due to a putative synergistic interaction among the selected constituents within the FM. Furthermore, other unidentified constituents of the oil (2.3\%), along with those that were not selected for this study (20.6\%), may exert antagonistic interactions that result in a reduction in the toxicity of the $I$. suffruticosa oil. Studying the toxicity of essential oils from Litsea pungens and Litsea cubeba as well as select compounds, Jiang et al. ${ }^{23}$ suggest that unidentified compounds could exert a synergic effect, since the oil demonstrated greater toxicity than the mixture against Trichoplusia ni. Similar results have been reported for mixtures of select compounds from the essential oil from Eugenia langsdorffii fruit. ${ }^{18}$ The present findings also suggest that the toxicity found for the Indigofera oil was intensified by the absence of some chemical constituents, enabling the formulation an acaricidal product with only the combination of select active components of the oil.

\section{Comparative toxicities of I. suffruticosa essential oil and its compounds}

To investigate the level of interaction of the constituents of the FM in the proportion at which these compounds were identified by CG-EM, fumigation tests were repeated with new blends prepared with the removal of one component at a time from the FM in the concentration at which the oil promoted $\geq 95 \%$ mortality $\left(4.8 \mu \mathrm{L} \mathrm{L}^{-1}\right.$ of air). Considering the two individually tested constituents that demonstrated greater toxicity than that found for the Indigofera oil (eugenol and thymol), only the experiment performed with the blend from which eugenol was removed demonstrated a drastic reduction in the mortality of the mites $(6.66 \%)$ (Figure 1), suggesting that this phenylpropanoid, in the proportion at which it occurs, is the compound that contributes most to the toxicity found for the FM. These results indicate that the fumigant action against $T$. urticae by blends of phenylpropanoids and terpenes as well as the Indigofera oil is related to complex, putative synergistic and/or antagonistic interactions, proportions among the constituents and individual toxicities.

\section{Ovicidal activity and oviposition deterrence of $I$. suffruticosa oil and main constituents}

Figure 2 displays the effects of the I. suffruticosa oil and select chemical constituents on the fecundity of T. urticae. The essential oil and its constituents demonstrated oviposition deterrent activity,

Table 2. Toxicity by fumigation ( $\mathrm{LC}_{\mathrm{so}}$ ) of $I$. suffruticosa essential oil and some constituents against T. urticae adult females

\begin{tabular}{|c|c|c|c|c|c|}
\hline Compound & $\mathrm{n}$ & df & slope & $\chi^{2}$ & $\mathrm{LC}_{50}(\mathrm{CI} 95 \%)$ \\
\hline Essential Oil & 540 & 4 & 1.88 & 9.34 & $0.900(0.610-1.290)$ \\
\hline FM & 450 & 3 & 1.10 & 5.47 & $0.002(0.001-0.004)$ \\
\hline Eugenol & 630 & 5 & 0.84 & 2.50 & $0.004(0.002-0.008)$ \\
\hline Thymol & 449 & 3 & 1.45 & 6.35 & $0.002(0.001-0.003)$ \\
\hline (E)-Nerolidol & 450 & 3 & 1.09 & 3.57 & $0.040(0.020-0.070)$ \\
\hline Safrole & 442 & 3 & 3.81 & 6.69 & $0.360(0.230-0.460)$ \\
\hline Dill apiole & 702 & 5 & 3.24 & 5.13 & $0.280(0.240-0.320)$ \\
\hline (Z)-asarone & 630 & 4 & 5.39 & 8.38 & $8.510(7.140-9.610)$ \\
\hline$(E)$-asarone & 540 & 3 & 6.93 & 6.84 & $6.640(5.050-7.700)$ \\
\hline
\end{tabular}

$\mathrm{LC}_{50}$ values are expressed in $\mu \mathrm{L} \mathrm{L}^{-1}$ of air. $\mathrm{FM}=$ full mixture, is composed by the 7 constituents based on the composition of the Indigofera sufruticosa oil as indicated by GC-MS analyses. $\mathrm{n}=$ number of mites/dose. $\mathrm{df}=$ degrees of freedom. $\chi^{2}=$ chi-squared. CI $=$ confidence interval. Columns followed by the same letter do not differ significantly based on the confidence interval $(P=0.05)$. 


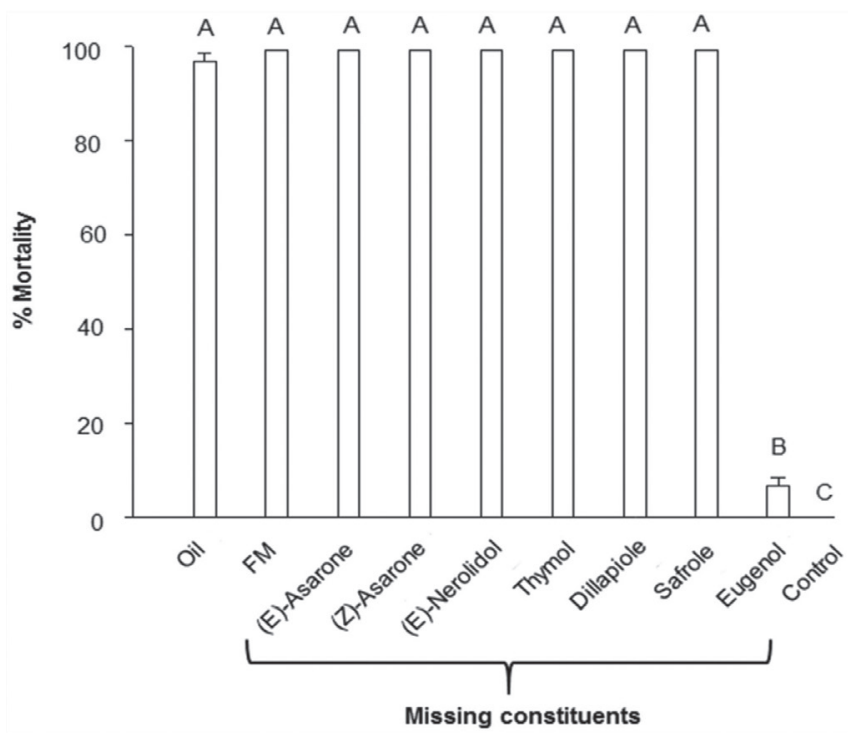

Figure 1. Fumigant activity of I. suffruticosa essential oil, complete blend and selected constituents on T. urticae adult females. Mortality caused by the vapor of the natural oils, complete blend, and selected blends of constituents of oil from the leaves of I. suffruticosa to T. urticae applied at levels equivalent to those found in the $\geq 95 \%$ lethal concentration of the natural oil $(4.8 \mu \mathrm{l}$ $L^{-1} \mathrm{of}$ air). Error bars represent the standard error of the mean of 90 mites. Means corresponding to each treatment with different letters are significantly different from each other according to the Tukey's test $(P \leq 0.05)$. FM $=$ full mixture, indicates a blend of 7 constituents, whereas all others indicate the full mixture missing the constituent noted as demonstrated by the reduction in the number of eggs laid by female mites in comparison to the controls. The strongest oviposition deterrent was safrole, followed by $(E)$-asarone and dill apiole. Evaluating the effects of the essential oil from Santalum album and its main compound (santalol) on the fecundity of T. urticae, Roh et al..$^{24}$ found that only the main compound demonstrated an oviposition deterrent effect. Moreover, Topuz and Erler $^{25}$ found that the essential oils from Laurus nobilis, Myrtus communis and Artemisia absinthum were toxic to adults and eggs of the mite T. cinnabarinus, demonstrating oviposition deterrent activity.

Ovicidal activity was measured by the percentage of nonviable eggs, as demonstrated in Figure 3. A significant difference was found among the treated samples $\left(\mathrm{F}_{8,18}=484.88, \mathrm{P}<0.001\right)$. After $24 \mathrm{~h}$ of exposure, eugenol and safrol exhibited the greatest ovicidal activity, with no significant difference in the percentage of nonviable eggs between these two substances. A previous study found that eugenol was also highly effective against the eggs of Pediculus capitis. ${ }^{26}$ In the present investigation, the Indigofera oil and the select compounds $(E)$-nerolidol, $(E)$ and $(Z)$-asarone demonstrated the lowest ovicidal activity, as the percentage of nonviable eggs promoted by vapours from the Indigofera oil did not differ significantly from the percentage obtained for these compounds mentioned. At $4.8 \mu \mathrm{L} \mathrm{L}^{-1}$ of air, the results obtained with Indigofera oil were similar to the ovicidal activity against $T$. urticae reported by Choi et al. ${ }^{27}$ for the essential oil from Citronella java using $4.7 \mu \mathrm{L} \mathrm{L}^{-1}$ of air. Moreover, the present results demonstrate that relatively low concentrations of Indigofera oil and some of its constituents have the potential to control the fecundity of $T$. urticae by reducing oviposition and the number of larvae that emerge after fumigation.

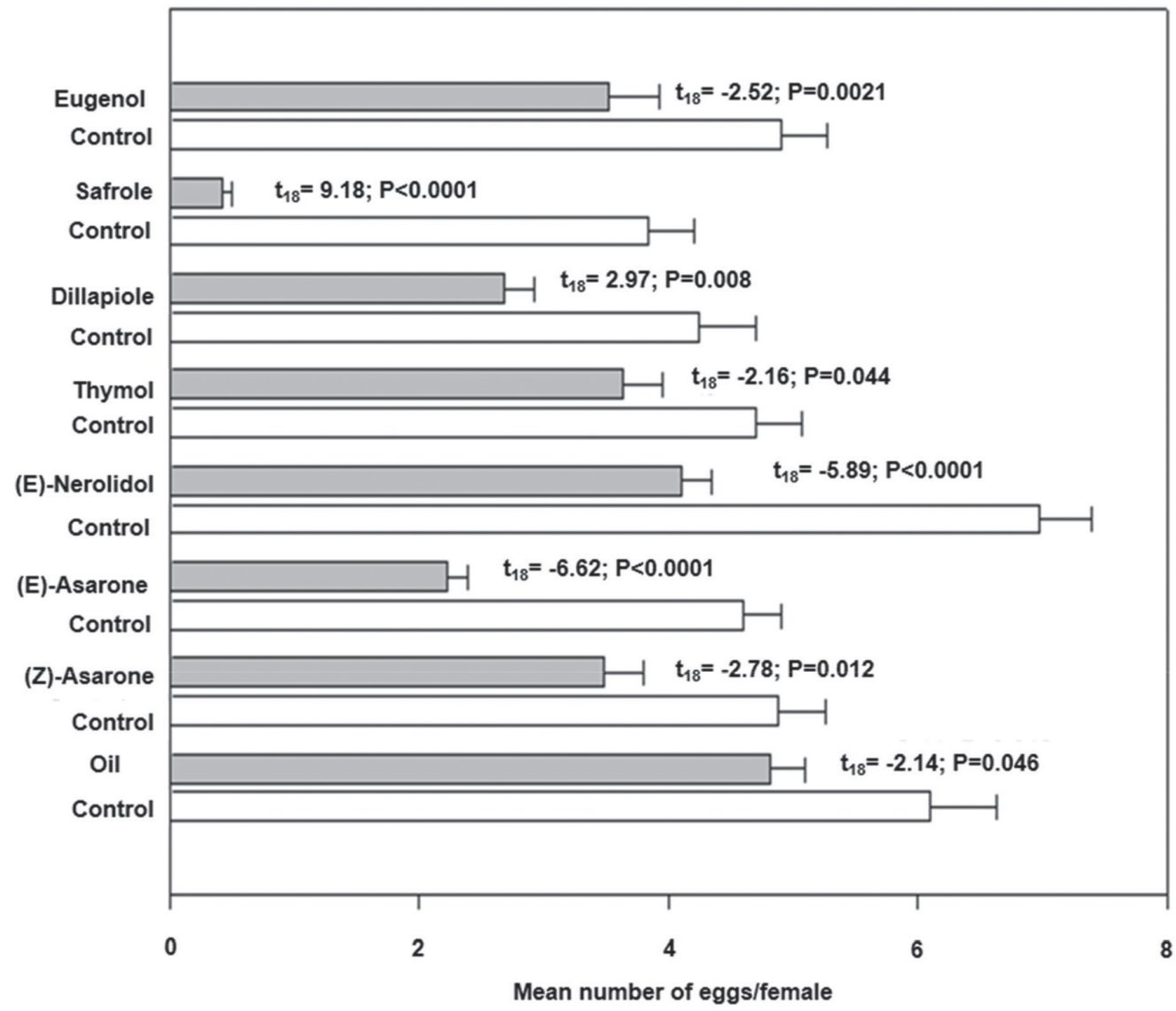

Figure 2. Effects of I. suffruticosa essential oils on oviposition deterrence of adult females T. urticae. The values represent the mean number of eggs laid per female of T. urticae when subjected to I. suffruticosa oil and selected constituents of the oil at the lowest concentration used in fumigation experiments that differed significantly from control. Means corresponding to each treatment (Tukey's test) 


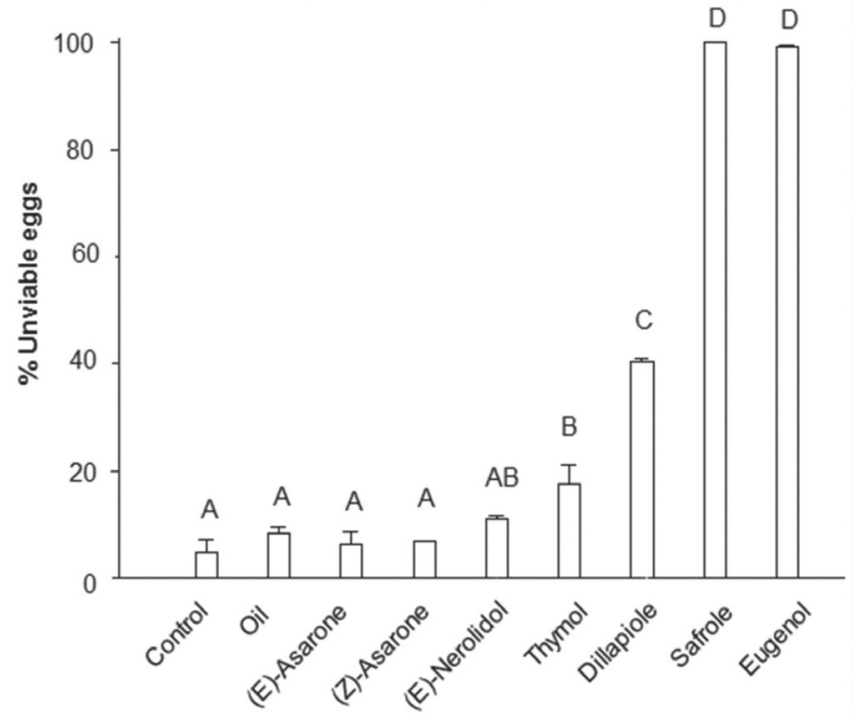

Figure 3. Ovicidal effect of I. suffruticosa essential oil and selected constituents in concentration $4.8 \mu L L^{-1}$ of air on T. urticae eggs. Means corresponding to each treatment with different letters are significantly different from each other according to the Tukey's test $(P \leq 0.05)$

\section{CONCLUSIONS}

The chemical composition of the essential oil from leaves of $I$. suffruticosa collected from a fragment of the Atlantic Forest in the state of Pernambuco, Brazil, constitutes a new chemotype for the genus, the major components of which are eugenol $(45.6 \pm 0.4 \%),(E)$ asarone $(17.4 \pm 0.2 \%)$ and dill apiole $(10.6 \pm 0.2 \%)$. The evaluation of the effects on adult and egg forms of the two-spotted spider mite, T. urticae, revealed that the oil and select constituents offer significant fumigant toxicity (eugenol and thymol), ovicida activity [(E)- and $(Z)$-asarone] and oviposition deterrence [safrole and (E)-asarone]. The test with the full mixture of the select compounds suggests that acaricidal products can be formulated with select compounds of the oil as the main active ingredient. The properties and results obtained herein for the essential oil from Indigofera suffruticosa make this oil a strong candidate for use as the active ingredient in a plant-based acaricidal product.

\section{SUPPLEMENTARY INFORMATION}

Supplementary data (Figure 1S) is available free of charge at http://quimicanova.sbq.org.br in PDF format.

\section{ACKNOWLEDGMENTS}

The authors are grateful to the Fundação de Amparo à Ciência e Tecnologia do Estado de Pernambuco (FACEPE), Conselho Nacional de Desenvolvimento Científico e Tecnológico (CNPq) and Coordenação de Aperfeiçoamento de Pessoal de Nível Superior for awarding a grant (CAPES - Proc. \# IBPG-0984-5.01/10; a productivity scholarship (CNPq, \# 312277/2013-0) and research funding for this study (CNPq \# PQ-2-302860/2016-9; FACEPE \# APQ-1008-1.06/15; APQ-0476-1.06/14; APQ-08601.06/16; IBPG0715-1.06/18; BCT-0185-1.06/17).

\section{REFERENCES}

1. Attia, S.; Grissa, K. L.; Lognay, G.; Heuskin, S.; Mailleux, A. C.; Hance, T. J.; Econ. Entomol. 2011, 104, 1220.

2. Sato, M. E.; Silva, M. Z.; Silva, R. B.; de Souza Filho, M. F.; Raga, A.; Arq. Inst. Biol. 2009, 76, 217.

3. Van Leeuwen, T.; Vontas, J.; Tsagkarakou, A.; Dermauw, W.; Tirry, L.; Insect Biochem. Mol. Biol. 2010, 40, 563.

4. Isman, M. B.; Miresmailli, S.; Machial, C.; Phytochem. Rev. 2011, 10, 197.

5. Araújo, M. J. C.; da Camara, C. A. G.; Born, F. S.; Moraes, M. M.; Badji. C. A.; Exp. Appl. Acarol. 2012, 57, 139.

6. Ribeiro, N. C.; da Camara, C. A. G.; Ramos, C. S. J.; Agr. Res. 2016, 76, 71.

7. Roh, H. S.; Lee, B. H.; Park. C. G.; J. Asia-Pac. Entomol. 2013, 16, 245.

8. Laborda, R.; Manzano, I.; Gamón, M.; Gavidia, I.; Pérez-Bermúdez, P.; Boluda. R.; Ind. Crop. Prod. 2013, 48, 106.

9. Hassen, A.; Rethman, N. F. G.; Niekerk, W. A.; Tjelele, T. J.; Anim. Feed Sci. Tech. 2007, 136, 312.

10. Almeida, E. R.; Plantas Medicinais Brasileiras: Conhecimentos populares e científicos, Hemus Ed., Ltda.: São Paulo, 1993.

11. Arriaga, A. M. C.; Lemos, T. L. G.; Santiago, G. M. P.; Andrade-Neto, M.; Braga, M.A.; Almeida, M. C. S.; Gomes, T. B. M.; Rodrigues, F. E. A.; Vasconcelos, J. N.; Pericles, B. A.; Chem. Nat. Compd. 2013, 49, 150.

12. Santos, A. T. B.; Araújo, T. F. D. S.; da Silva, L. C. N.; Silva, C. B. D.; Oliveira, A. F. M. D.; Araújo, J. M.; Correia, M. T. S.; Lima, V. L. M.; Front Microbiol. 2015, 6, 1.

13. POLO - PC: A User's Guide to Probit Logit Analysis, LeOra Software, California, 1987.

14. Van Den Dool, H.; Kratz, P. D.; J. Chromatogr. A 1963, 11, 463.

15. Adams, R. P.; Identification of Essential Oil Components by Gas Chromatography/Quadrupole Mass Espectroscopy, $4^{\text {th }}$ ed., Allured Publishing Corporation: Carol Stream, 2007.

16. Pontes, W. J. T.; Oliveira, J. C. S.; da Camara, C. A. G.; Lopes, A. C. H. R.; Godim-Júnior, M. G. C.; Oliveira, J. V.; J. Essent. Oil Res. 2007, 19, 379.

17. SAS user's guide: Statistics, version 9.0, $7^{\text {th }}$ ed., SAS Institute: Cary, 2002.

18. Moraes, M. M.; da Camara, C. A. G.; Santos, M. L.; Christopher, F. A. G. G.; J. Braz. Chem. Soc. 2012, 239, 1647.

19. Arriaga, A. M. C.; Neto, M. A.; Malcher, G. T.; Gomes, T. B. M.; Vasconcelos, J. N.; Rodrigues, A. C. P.; Santiago, G. M. P.; Chem. Nat. Compd. 2008, 44, 193.

20. Neves, I. A.; Oliveira, J. C. S.; da Camara, C. A. G.; Schwartz, M. O. E.; J. Essent. Oil Res. 2008, 20, 157.

21. Kräutler, B. In The Porphyrin Handbook: Chlorophylls and bilins: Biosynthesis, Synthesis and Degradation; Kadish, K. M., Smith, K. M., Guilard, K. M. R., eds.; Elsevier Science Publishing: New York, 2003.

22. Cavalcanti, S. C. H.; Niculau, E. S.; Blank, A. F.; da Camara, C. A. G.; Araújo, I. N.; Alves, P.B.; Bioresour. Technol. 2010, 101, 829.

23. Jiang, Z.; Akhtar,Y.; Bradbury, R.; Zhang, X.; Isman, M. B.; J. Agr. Food Chem. 2009, 57, 4833.

24. Roh, H. S.; Lim, E. G.; Kim, J.; Park, C. G.; J. Pest. Sci. 2011, 84, 495.

25. Topuz, E.; Erler. F.; Environ. Bull. 2007, 16, 1498.

26. Yang, Y. C.; Lee, S. H.; Lee, W. J.; Choi, D. H.; Ahn, Y. J.; J. Agr. Food Chem. 2003, 51, 4884.

27. Choi, W. I.; Lee, S. G.; Park, H. M.; Ahn, Y. J.; J. Econ. Entomol. 2004, 97, 553. 